\title{
RESEARCH ON INNER SURFACE OF HYDROFORMED TUBES
}

\author{
Vasile Adrian Ceclan ${ }^{1}$, Sorin Dumitru Grozav ${ }^{2}$, Ivan Kuric ${ }^{3}$ \\ 1 Technical University of Cluj Napoca, Faculty of Machine Building, Blv Muncii 103-105, Cluj Napoca, Romania, \\ e-mail: vasile.ceclan@tcm.utcluj.ro \\ 2 Technical University of Cluj Napoca, Faculty of Machine Building, Blv Muncii 103-105, Cluj Napoca, Romania, \\ e-mail: sorin.grozav@tcm.utcluj.ro \\ ${ }^{3}$ University of Žilina, Faculty of Mechanical Engineering, Univerzitna 1, 010 26, Žilina, Slovakia, \\ e-mail: ivan.kuric@fstroj.uniza.sk
}

Received: 2017.10.25

Accepted: 2017.11.13

Published: 2017.12.05

\begin{abstract}
In this paper a reserch regarding the surfece of hydroforming tubs, made by aluminium and cooper is presented. Tube hydroforming is very important production method considering that metal tubes are widely used in a great variety of engineering products, such as automobile, aircraft, air conditioner, air compressor, exhaust systems, fluid lines. The results show that the surface of tubes it is influence of the hydroforming process. the material of the tube in research of surface is also very important.
\end{abstract}

Keywords: surface, hydroforming, tubes

\section{INTRODUCTION}

Hydroforming is a manufacturing process that uses hydraulic pressure to produce the straining of a blank sheet or a tubular part. Hydroforming has an important role in the automotive industry due to its capability to produce stiff components with hollow configurations. This combination of characteristics leads to lighter and more rigid vehicle constructions. The automotive industry is one of the domains in which the hydroforming has extensive applications but, as mentioned above, the applicability is not limited to vehicles [1]. Tubular hydroforming method is frequently used to make complex parts at the structure of automotive and also in the other sectors of manufacturing (aeronautical parts, industrial parts). This method is a cold deforming process, and we can obtain the form that we want by one single operation. At present, this procedure is being assimilated in many other industrial areas (aerospace, household appliance industry), as it is presented in Figure 1. The suspended surface is divided into two regions, the trend of material flow is studied in the geometric view, and predicts the possibility of the wrinkling. The wrinkling of the suspended surface is not only related to the geometry of the part, but also to the loading path. Qualitative analysis of wrinkling is controlled by adjusting the parameters about loading path, and get the relationship of pressure and punch stroke when the wrinkle happens. The qualified parts can be obtained in each process by optimising the parameters in the process of loading [2].

Figure 2 shows different stages of the hydroforming process. As can be seen, the first step is to place the tube in the open mold. The second step is to close the tool with the internal pressurization of the piece. The most important step is to push under the increasing pressure exerted by the hydraulic agent. This pressure forces the tube to copy the internal geometry of the hydroforming matrix.

Figure 3 shows the process of hydroforming tubular parts. With this method of hydroforming the tubular parts $\mathrm{CNC}$ machine tools were also put into practice. These machines have high productivity in the execution of parts of different shapes and high complexity.

This principel can be used for normal tubs, but also for tubes which have been previously 


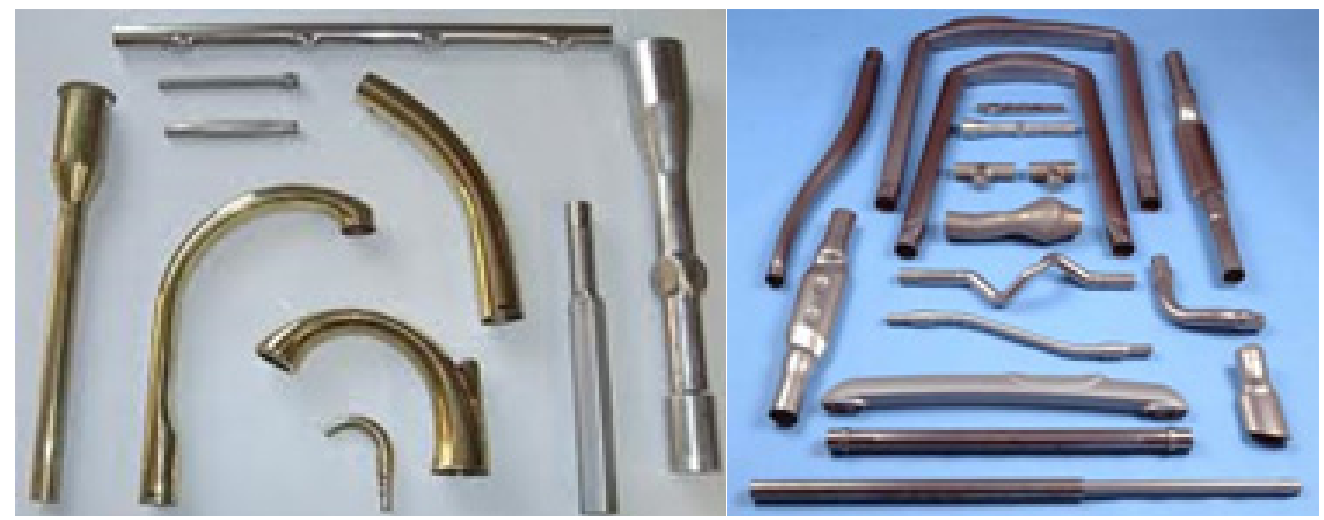

Fig. 1. Tubular hydroforming parts

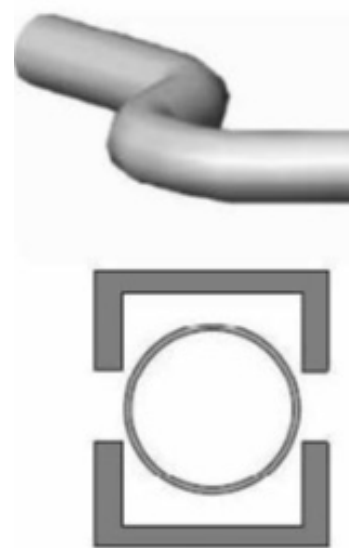

a)

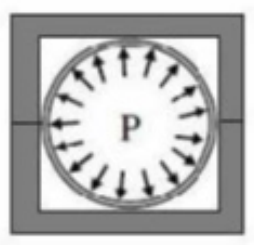

b)
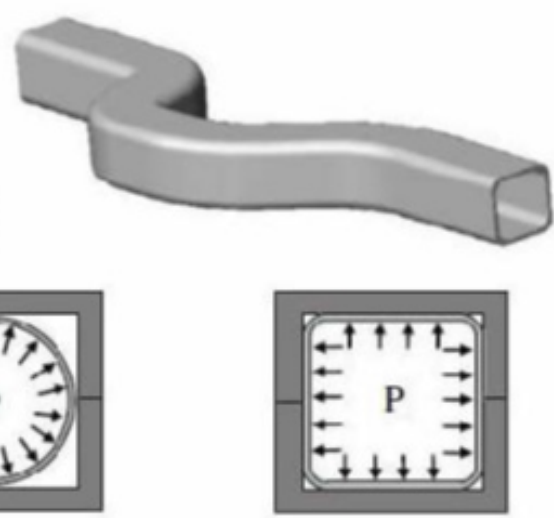

c)

Fig. 2. Tubular hydroforming parts [3]

bent. This type of tubes can have diferent wall thickness but, this wall influences the presure in the process. With this principel it can be made also 3D parts, with diferent angles. Rectangular section parts created through hydroforming have good application prospects in the automotive industry because of their advantages of simple manufacturing procedure, high forming quality, and greater bending module than circular crosssectional parts. Forming quality is directly influenced by the formed corner parameters of rectangular section parts. It is also a difficult matter in rectangular section hydroforming [4].

Sample's roughness of the inner surface of tubes was measured and it was considered whether the sample properties are according to EN 10305-1. Principle of measurement: the sensing tip of the arm moves at a constant speed across the surface and picks up its inequality. The device provides output of numerical values for the standard characteristics of surface roughness on the display or graphical output (measured profile and curve of the material profile share) in the monitor [5].

\section{MECHANICAL CHARACTERISTICS}

The tensile tests have been performed using non-proportional dog-bone specimens. The specimens have been obtained by machining. According to EN 10002-1:1995, the curvature of the central region corresponding to the calibrated length Lc should not be modified. In contrast, the ends of the specimen can be flattened in order to ease their clamping in the tensile testing device. The standard also mentions that the calibrated region should be connected to the ends by fillet radii of at least $12 \mathrm{~mm}$. The specimens were cut longitudinally from aluminum and copper tubes having an outer diameter of $35 \mathrm{~mm}$. In order to avoid any significant alteration of the microstructure and material parameters, the specimens have been separated from the tubular product using water-jet cutting machine OMAX [6].

Figure 5 shows the water jet cutting machine as well as the sampling phases.

These specimens were collected by this method, as it does in this way were able to obtain 


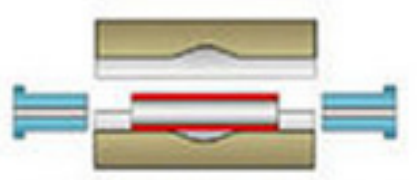

POSITIONING OF TUBE

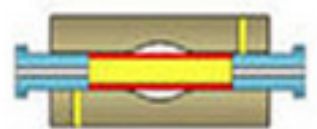

ACTUATORS WORK
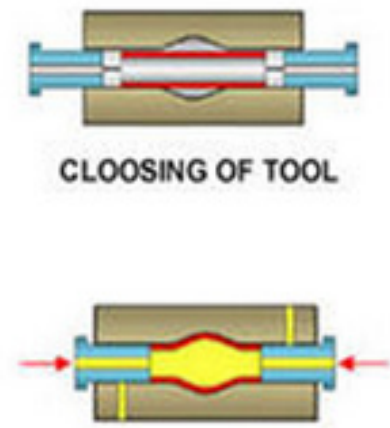

FORMING FLUID UNDER PREASSURE
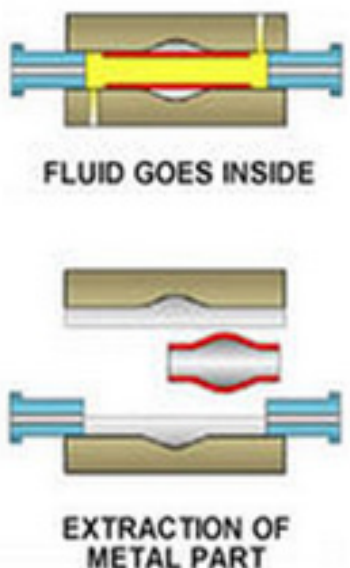

Fig. 3. Principel of hydroforming tubular parts
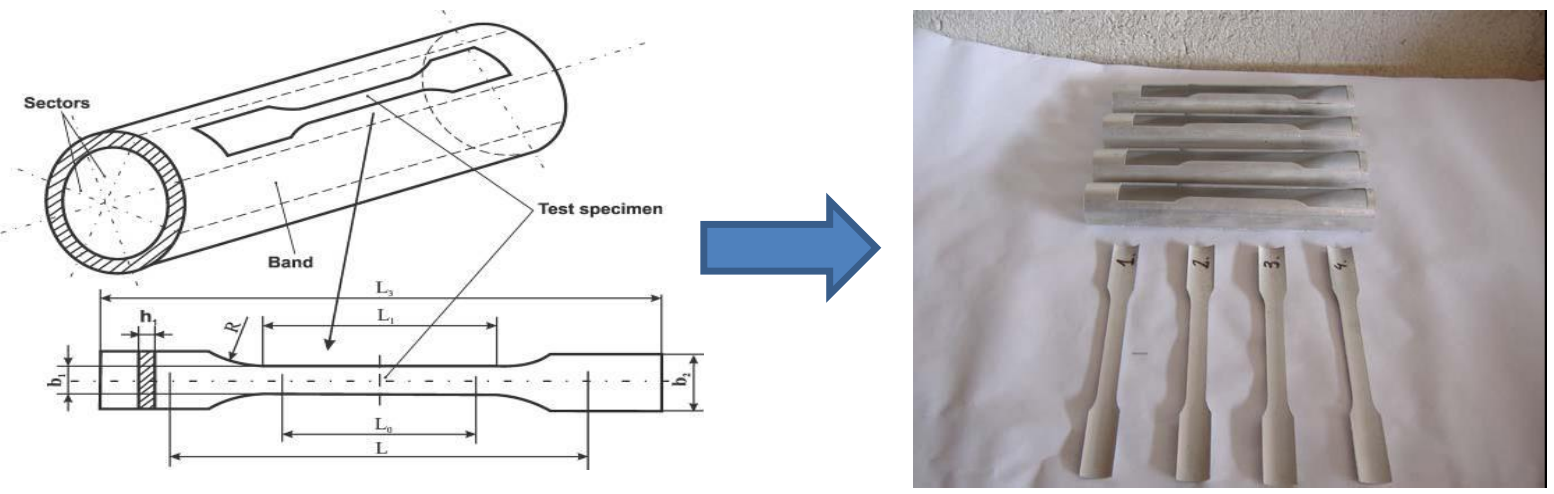

Fig. 4. Shape and dimensions of the specimen subjected to tensile testing [7]
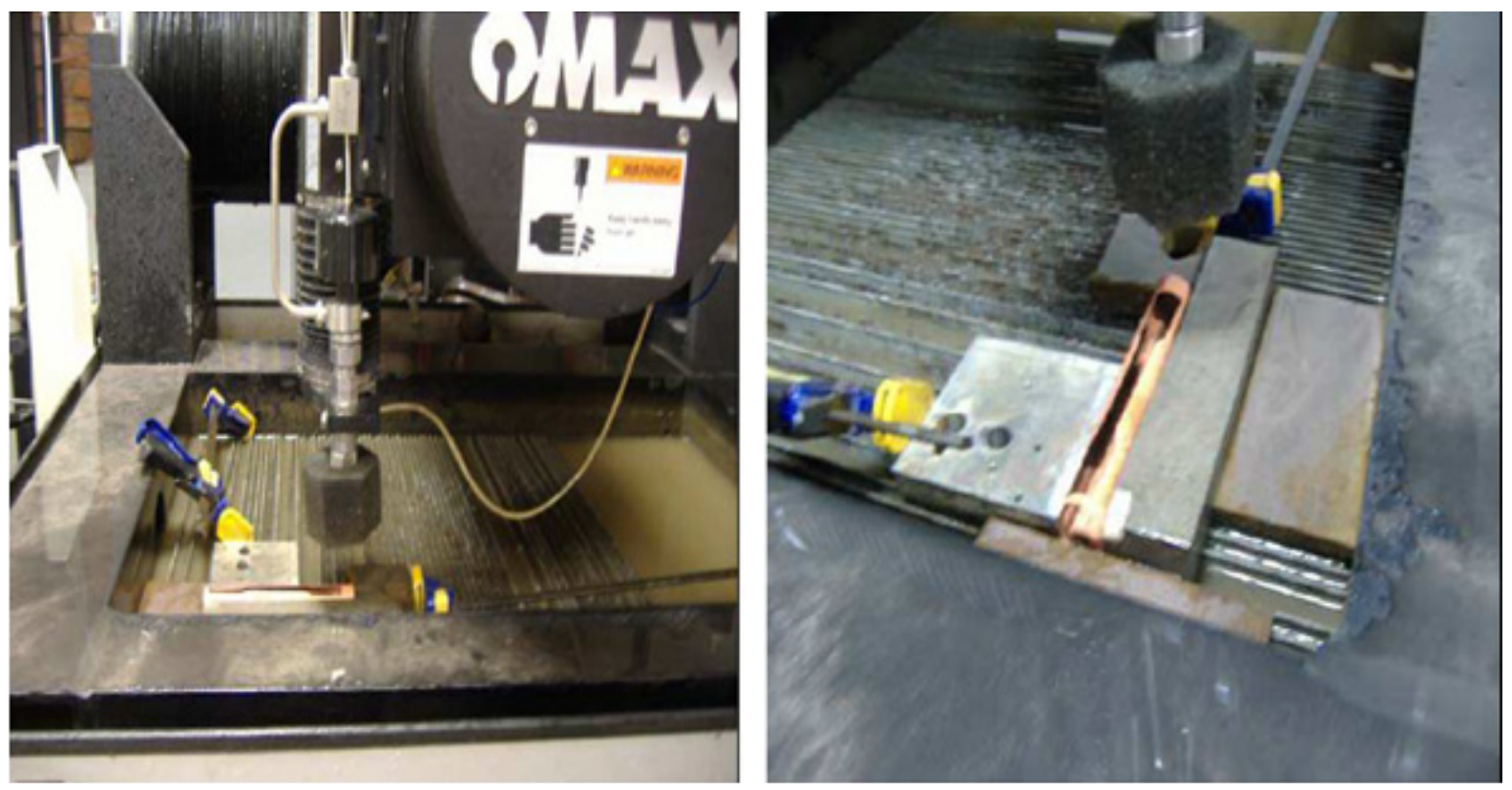

Fig. 5. Water-jet cutting machine OMAX 2626 
specimens for tensile testing without affecting the mechanical properties [7] and material characteristics of the tubular speciments [9]. These propreties are very good for numerical simulation of the process [10].

In Table 1 the dimensions of the specimens that have been taken from the tubes to determine the characteristics of the material are presented. These dimensions were for both aluminium and copper tubes.

Table 2 shows the main mechanical characteristics of the tubes following the tests. After mechanical tests it can be observed that the deformation of the tubes is very good, therefore, they are suitable for hydroforming.

\section{MOLD OF THE HYDROFORMING TUB}

The aims of hydroforming process were the deformability analysis of the tube and the changes of the wall thickness in the case of hydroformed parts. For this, it was necessary to design and manufacture a hydroforming mold.

The hydroforming mold is composed of following parts (Fig. 6):

1. Tubular sample. This was make by cooper material $(\mathrm{Cu} 99,9)$, taken from tubular part with outer diameter of $\varnothing 35[\mathrm{~mm}]$ and a length of $5000[\mathrm{~mm}]$. The wall thickness was $1 \mathrm{~mm}$.

2. Sealing parts, was made by tubular silicone with length of $20[\mathrm{~mm}]$ and inside diameter of $\varnothing 22 \mathrm{~mm}$; outside diameter was $\varnothing 33[\mathrm{~mm}]$.

3. Mobile plunger was made of OLC 45 material. Inside of the plunger, a hole for the hydraulic oil has been designed and manufactured.

4. Fix plunger was made of OLC 45 material.
This item has the role of lining-up and guiding the hydroforming mold.

5. The two parts of the mold were made of OL 37 material, having the dimensions $300 \times 160 \times 40$ $\mathrm{mm}$. These two parts of the mold were milled on a CNC Machine.

\section{EXPERIMENTAL RESEARCH}

This paper aims at determining the roughness of the tube surfaces before and after hydroforming. Rugosity is very important in order to be able to see the quality of the surface of the tubes as a result of their deformation processes. We performed some tests on the tubes before deforming and after. Figure 7 shows the measurement of roughness on the copper tubes before hydroforming. Figure 8 shows the measurement of roughness on the copper tubes after hydroforming.

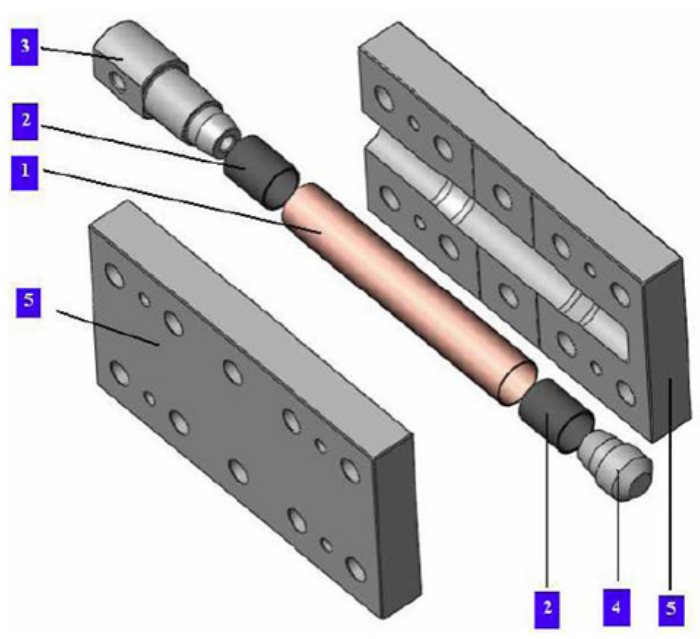

Fig. 6. The hydroforming mold

Table 1. Dimension of the tensile test specimens

\begin{tabular}{|c|c|c|c|}
\hline Symbol & Size & Symbol & Size \\
\hline $\mathrm{L}$ & $105[\mathrm{~mm}]$ & $\mathrm{R}$ & $30[\mathrm{~mm}]$ \\
\hline $\mathrm{L}_{0}$ & $50[\mathrm{~mm}]$ & $\mathrm{h}$ & $1.5[\mathrm{~mm}]$ \\
\hline $\mathrm{L}_{1}$ & $75[\mathrm{~mm}]$ & $\mathrm{b}_{1}$ & $12.5[\mathrm{~mm}]$ \\
\hline $\mathrm{L}_{3}$ & $195[\mathrm{~mm}]$ & $\mathrm{b}_{2}$ & $20[\mathrm{~mm}]$ \\
\hline
\end{tabular}

Table 2. Characteristics of material obtained from tensile tests

\begin{tabular}{|l|c|c|}
\hline Feature material & Al 99.5 & Cu 99.9 \\
\hline Tensile strength $\mathrm{R}_{\mathrm{m}}$ & $77,1 \mathrm{MPa}$ & 232,7 \\
\hline Conventional yield stress $\mathrm{R}_{\mathrm{p} 0,2}$ & $58,9 \mathrm{MPa}$ & 52 \\
\hline Percent elongation under maximum load $\mathrm{A}_{\mathrm{g}}$ & $13,5 \%$ & 32,7 \\
\hline Total elongation under maximum load $\mathrm{A}_{\mathrm{gt}}$ & $18,7 \%$ & 38.4 \\
\hline
\end{tabular}




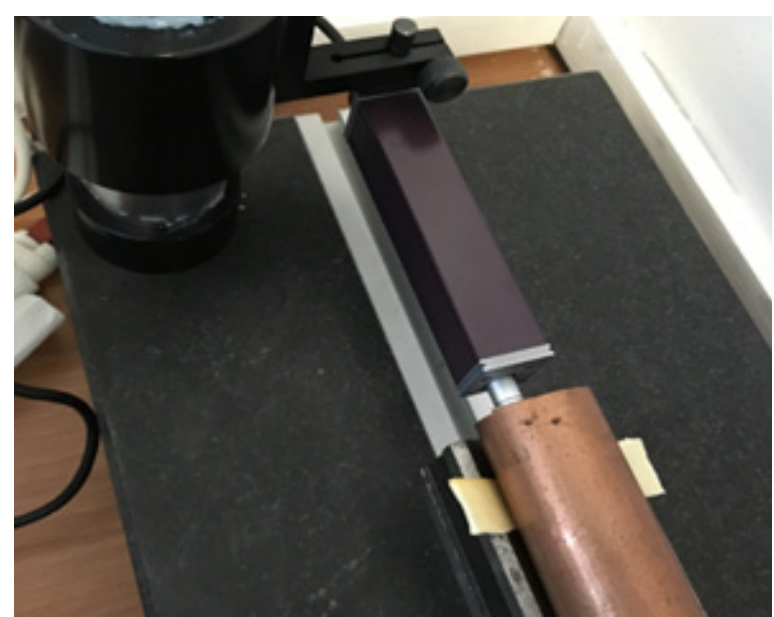

Fig. 7. Measurement of the inner surface at copper tubes before hydroforming

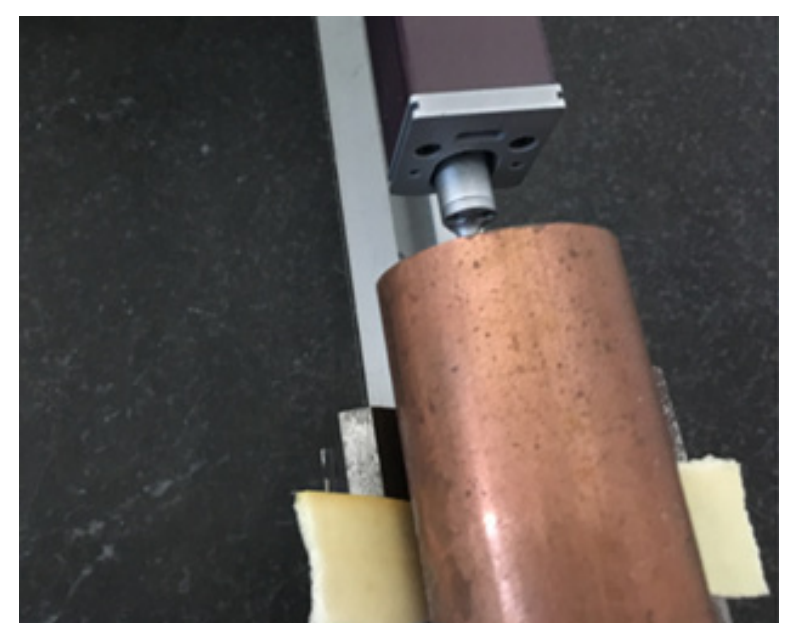

Fig. 8. Measurement of the inner surface at copper tubes after hydroforming

Table 3. The roughness of the copper tubes before hydroforming

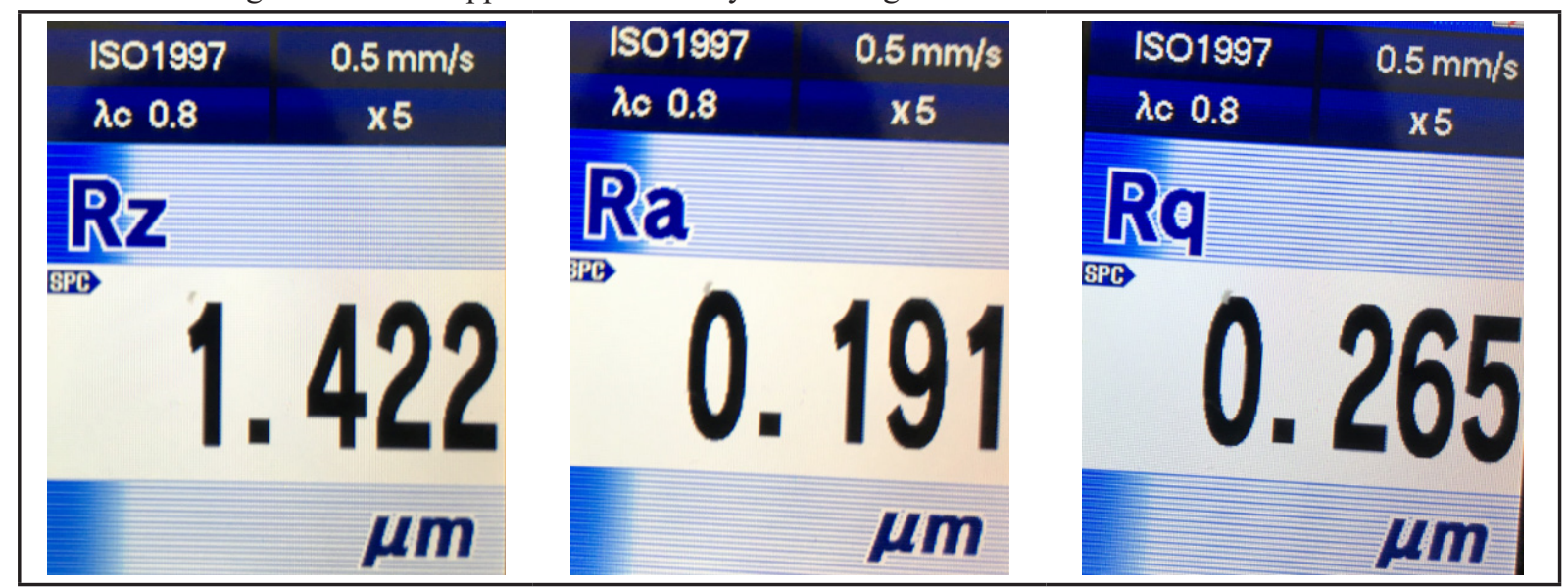

Table 4. The roughness of the copper tubes after hydroforming

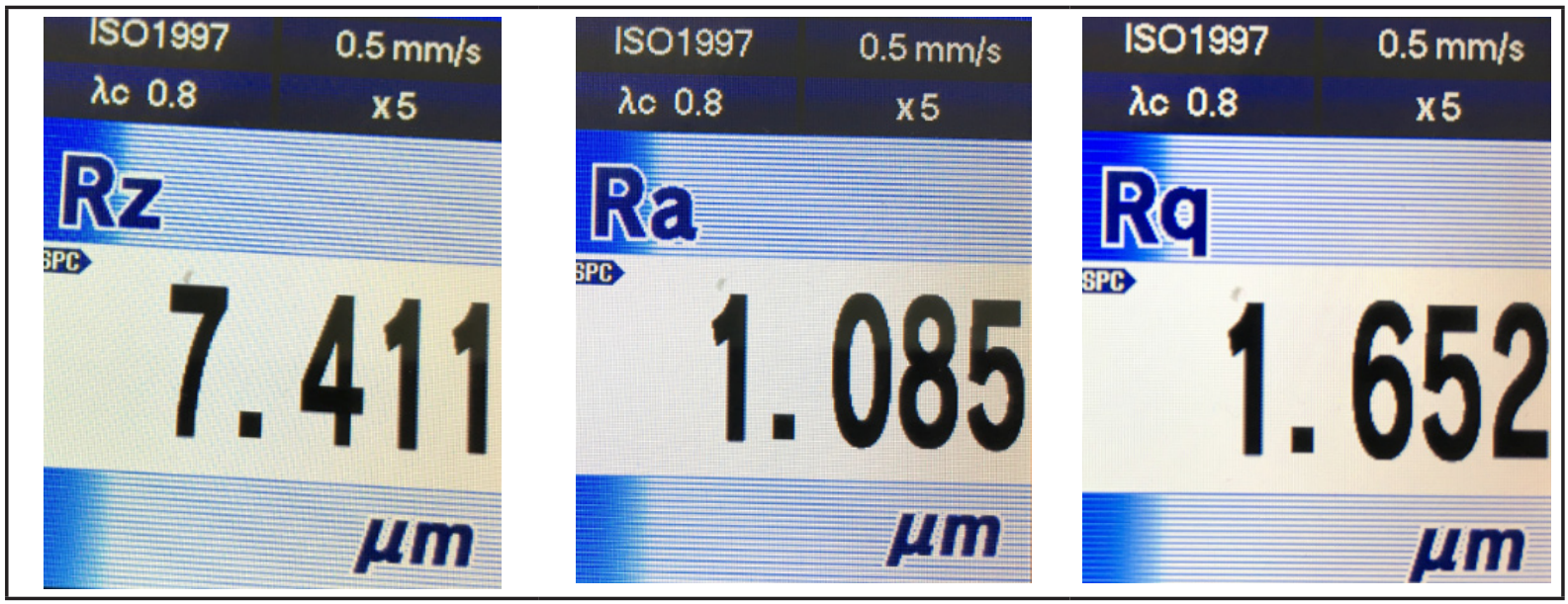


Figure 9 shows the measurement of roughness on the aluminium tubes before hydroforming.

\section{CONCLUSIONS}

Tube hydroforming processes is a new and advanced method the manufacturing tube parts, and it has a wide range of applications, being used in the automotive industry. Material parameters are very important in obtaining approximations real as the hydroforming process. Tensile tests are obtained through a set of mechanical characteristics precise enough to simulate the desired deformation.

As you can see, the hydroforming process influences the inner surface of the tube very much. For this reason a better determination of the in-

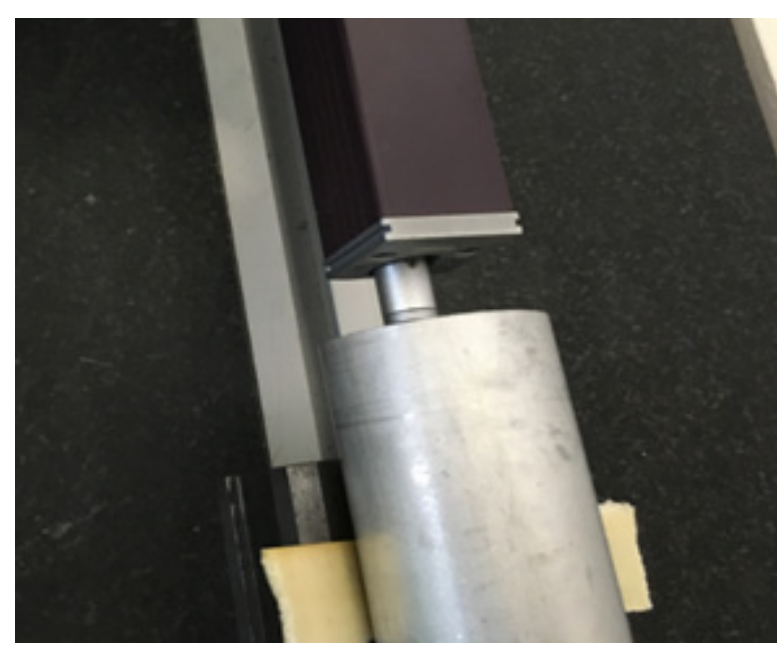

Fig. 9. Measurement of the inner surface at aluminium tubes before hydroforming ner surface must be made in the wall in which the tube will have to flow a fluid. The hydroforming process has a higher effect on the inner surface of the more deformable materials.

It is very important to determine the most accurate of the inner surface. If a better measurement is made, it is helpful to carry out a numerical simulation for the liquids flowing inside the hydroformed tubes.

\section{Acknowledgement}

This work was supported by a grant of the Romanian National Authority for Scientific Research and Innovation, CNCS/CCCDI-UEFISCDI, project number PN-III-P2-2.1-BG-2016-0216, within PNCDI III.

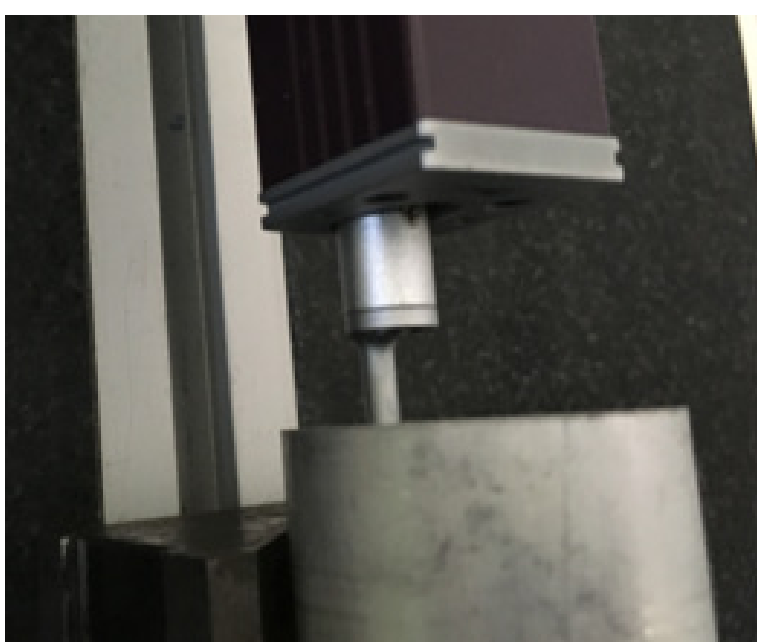

Fig. 10. Measurement of the inner surface at aluminium tubes after hydroforming

Table 6. The roughness of the aluminium tubes after hydroforming

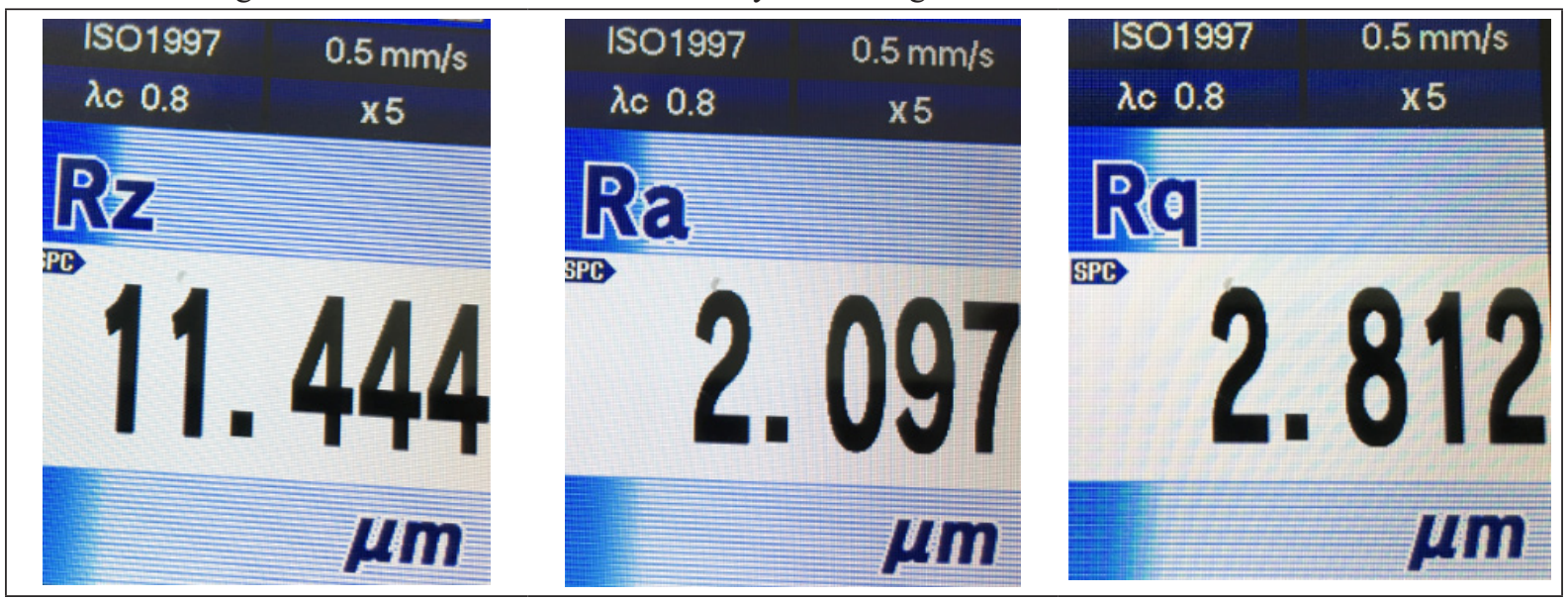


Table 5. The roughness of the aluminium tubes before hydroforming

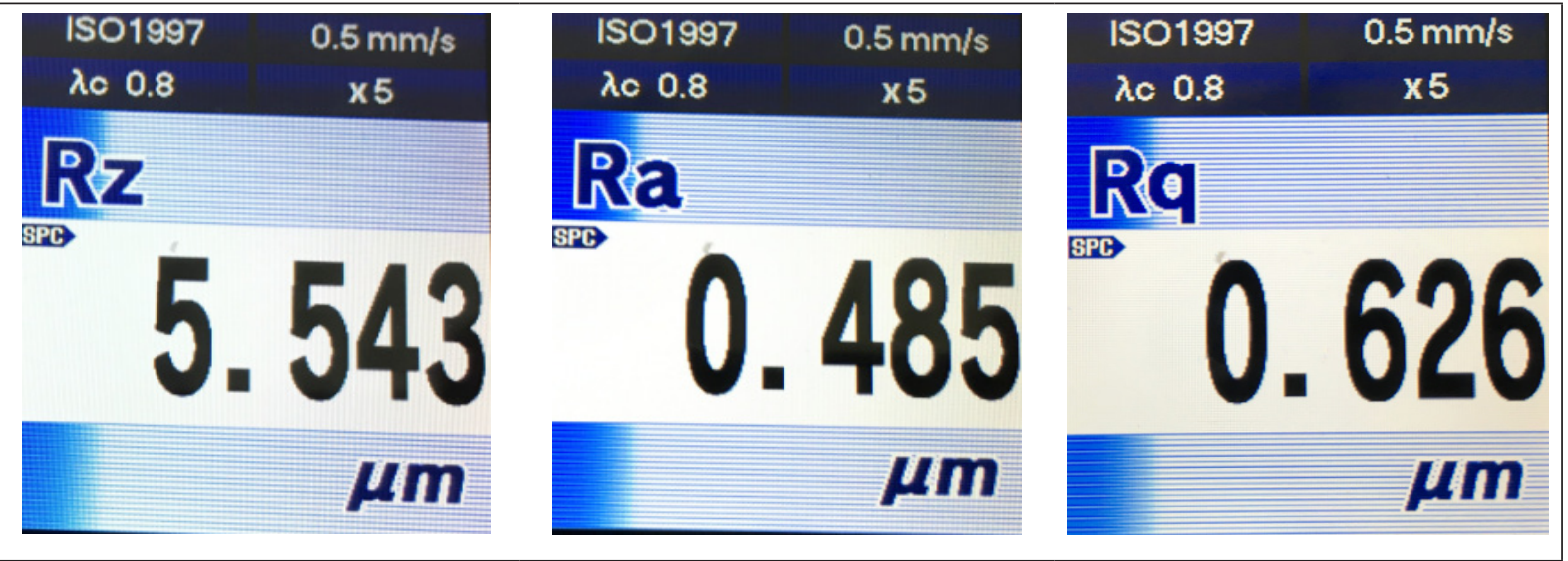

\section{REFERENCES}

1. Ceclan V., Grozav S., Sabau E., Popan I.A., Borzan C.,: Structural analysis of tubes hydroforming, AJME-2013, Vol. 11, Issue 4, ISSN 1583-7904, pg. 56-59;

2. Sun, ZY, Lang, LH, Li, K, Wang, Y, Zhang, QD, : Study on the mechanism and the suppression method of wrinkling in side wall using hydroforming of the fairing, INTERNATIONAL JOURNAL OF ADVANCED MANUFACTURING TECHNOLOGY Volume: 90 ,Issue: 9-12 Pages: 2527-2535,

3. Koç, M. (ed.) Hydroforming for Advanced Manufacturing. Cambridge: Woodhead, 2008.

4. Jia, YK ,Li, J , Luo, JB : Analysis and experiment on tube hydroforming in a rectangular cross-sectional die, ADVANCES IN MECHANICAL ENGINEERING Volume: 9 Issue: 5

5. Martin RIDZOŇ, Lubica ELEKOVÁ, Jana LIŠKOVÁ, Jozef BÍLIK: Effect of reduction in three-drawn and two-drawn single-run technology on roughness of inner surface of tubes, 2010, Volume 18, Number 28

6. Popan Alexandru, Balc Nicolae, Carean Alexandru, Luca Alina, Miron Alin, :Research to improve the surface roughness of the parts made by water jet milling, AJME-2013, Vol. 11, Issue 2, ISSN 1583-7904, pg. 105-109;

7. V. Ceclan, N. Balc, A. Miron, C. Borzan, I.A. Popan,
:Numerical simulation of the tube bending process and validation of the results, Academic Journal of Manufacturing Engineering, AJME-2011, Vol. IX, Issue 3, ISSN 1583-7904, pag. 32-37;

8. Popan I.A., Balc N., Carean A., Luca A., Miron A.,:Research on Abrasive Water Jet Milling of The Planar Surfaces, Slots and Profiles, ICAMaT 2014 - 7th International Conference on Advanced Manufacturing Technologies, 23-24 October 2014, POLITEHNICA University of Bucharest, Applied Mechanics and Materials Vol 760 (2015) pp 409-414,

9. Popan I.A., Balc N., Carean A., Luca A., Miron A.,:Research on Abrasive Water Jet Milling of The Planar Surfaces, Slots and Profiles, ICAMaT 2014 - 7th International Conference on Advanced Manufacturing Technologies, 23-24 October 2014, POLITEHNICA University of Bucharest, Applied Mechanics and Materials Vol 760 (2015) pp 409-414

10. P Bella, P Buček, M Ridzoň, M Mojžiš, L Parilák: Numerical simulation of multi-rifled tube drawing - finding proper feedstock dimensions and tool geometry, Materials Science and Engineering 179 (2017) 012008 doi:10.1088/1757-89 9X/179/1/012008.

11. Ridzoň M., (2012), The Effect of Technological Parameters Influencing the Properties of Seamless Cold-Drawn Tubes. - 1. ed. - (Hochschule Anhalt, Köthen). 89 p. 